\title{
Structural Strength and Service Life of the Extrusion Forming Die for Agricultural Engine Piston Heads
}

\author{
L. Q. Yang, ${ }^{a}$ Q. Q. Lv, ${ }^{\mathrm{a}, \mathrm{b}}$ H. M. Zhang, ${ }^{\mathrm{a}}$ C. H. Zhu, ${ }^{\mathrm{a}}$ and W. Z. Wang ${ }^{\mathrm{a}, 1}$ \\ a School of Mechanical and Electrical Engineering, Henan Agricultural University, China \\ ${ }^{\mathrm{b}}$ School of Mechanical and Electrical Engineering, Zhengzhou Technology and Business University, \\ Zhengzhou, China \\ ${ }^{1}$ bbgg2005@sina.com
}

Three-tier high-strength prestressed combination concave dies are designed to manifacture highpower corn combine harvester engine piston heads. This design integrates the advantages of traditional casting or hot die forging and warm extrusion. The following key parameters, viz radial dimensions of each mating layer, axial bonding and radial contact interaction, are obtained by theoretical calculation. Nonlinear analysis of the contact interaction was carried out, and the die contact condition was studied at no-load and full-load. Based on the Archard wear theory, thermomechanical bonding was studied in operation of the die. Through numerical simulation of the die wear in each operation cycle, the univariate linear regression equation of the die service life was derived, and the reliability of this equation was verified. The results show that the die contact is both stable and reliable if the radial contact interaction of the inner and outer layers is $\delta_{2}=1.9716 \mathrm{~mm}$ and $\delta_{3}=1.3870 \mathrm{~mm}$, respectively. With the nitriding layer thickness of $0.24 \mathrm{~mm}$, the extrusion die service life in the production of piston heads corresponds to 6357 pieces.

Keywords: engine piston head, combination concave die, extrusion, structural strength, wear, service life.

Introduction. With the acceleration of land circulation and industrialization of corn production, the degree of corn harvest mechanization becomes higher and higher. Biological and environmental factors enhance the further development of corn combine harvesters in the directions of high power, efficiency, low consumption and high intelligence [1]. On the other hand, heavy-duty operational conditions of harvester engines deteriorate their performance $[1,2]$ and results in the failure, in particular, of the engine piston heads. Given this, the improvement of piston head manufacturing technology is an urgent problem [3].

Traditionally, piston heads are manufactured by hot die forging or casting. Hot die forging can obtain the ideal mechanical performance for the piston head, but because of its strong oxidation [4], dimensional accuracy cannot be guaranteed when the shape of the piston head is complex and difficult to process. The casting method can produce more complex shapes of pistons, but it is prone to loosening, shrinkage, segregation and other defects. The resulting mechanical properties are usually unsuitable for high-performance engine piston head manufacturing [5]. Pistons produced by the traditional technology cannot meet the requirements of the high-performance engines of corn combine harvesters. Thus, the warm extruding technology is put forward.

The three-dimensional model of the engine piston head of the corn grain harvester is shown in Fig. 1. During the warm extruding technology's forming process, the tangential stress of the concave die is as high as $2312 \mathrm{MPa}$ [6]. Generally, high speed steel does not allow more than $2200 \mathrm{MPa}$ [7], so the concave die and double-layer die have no practical value. It is estimated that the die structure must adopt the three-layer prestressed combination die. Benefits of this approach include distribution of the tangential stress of the die, partial or complete cancellation of the tangential tensile stress acting on the inner wall of 
the die during the extrusion, prevention of concave die cutting to crack, and avoidance of cross section mutation at the place of stress concentration, which actively protects the mould.

\section{Experiments.}

1.1. Combined Concave Structure Design. The three-tier prestressed combination concave die structure size: $d_{1}=114 \mathrm{~mm}, d_{2}=186 \mathrm{~mm}, d_{3}=292 \mathrm{~mm}$, and $d_{4}=570 \mathrm{~mm}$. The corresponding available radial interference $\delta_{2}=1.9716 \mathrm{~mm}$ and $\delta_{3}=1.3870 \mathrm{~mm}$. Each layer adopts a surface taper of $\gamma=1.5^{\circ}$. The inner layer uses tungsten HSS $\mathrm{W} 18 \mathrm{Cr} 4 \mathrm{~V}$, the middle layer uses high toughness die steel $65 \mathrm{Cr} 5 \mathrm{Mo} 3 \mathrm{~W} 2 \mathrm{VSiTi}$, and the outer layer uses $\mathrm{Cr} 12 \mathrm{MoV}$. In order to ensure the durability of the mold, the mold cavity surface is treated with nitriding to a nitrided layer thickness of about $0.24 \mathrm{~mm}$ [8]. The structure diagram is shown in Fig. 2.
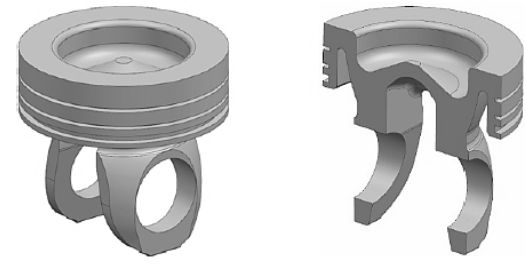

Fig. 1. 3D modeling of piston head.

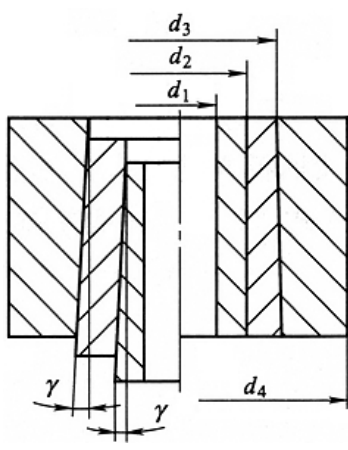

Fig. 2. Sectional female die structure size diagram.

1.2. Structure Strength Analysis of Combination Concave Die. According to the results of the mold design, the three-dimensional assembly model of the combination concave die was built. For the three-layer prestressed combination concave die, although the cavity structure is more complex, the principle is still the extrusion cylinder model [9], the concave mold cavity shape has little to do with this question. Therefore, it can be simplified into a three straight wall form. This significantly reduces the calculation time of the three-dimensional model, improving the solving efficiency.

When the relevant control parameters were set up in ANSYS software, the unilateral interference amount was set at 0.9858 and $0.9858 \mathrm{~mm}$, respectively. In order to facilitate the comparison, both die no-load and work force of the two states were analyzed. The analysis considers the working in the extrusion process, the stress field of the die, and the complexity of the temperature field. Thus, the use of a uniformly distributed load is adopted instead of the uniformly distributed load applied on the inner wall of the concave die. Since the edges have sharp corners, the true stress distribution during operation is not properly accounted for, and the edge effect is disregarded [10].

1.2.1. Contact State Analysis. The contact state is analyzed in order to study the layer combination of the con-cave die. When a combined concave die is working in a strong three-way stress state, the mating surface of each layer of mutual contact is uniform and reliable; this directly determines the reliability and stability of the die. Figures 3 and 4 show the contact state of the die at no load and during loading.

As can be seen from Figs. 3a and 4a, the mating surfaces of the die are in good and uniform contact with each other, in the ideal bonding state (sticking), regardless of whether the die is working or not. Figures $3 b$ and $4 b$ show the contact frictions between the two layers of the die in two cases, with maximum values of $134.36 \mathrm{MPa}$ and $604.48 \mathrm{MPa}$, respectively. Figures $3 \mathrm{c}$ and $4 \mathrm{c}$ show the normal stress of the contact between the two layers in the two cases. The maximum values are 390.7 and $2270 \mathrm{MPa}$, respectively. In 


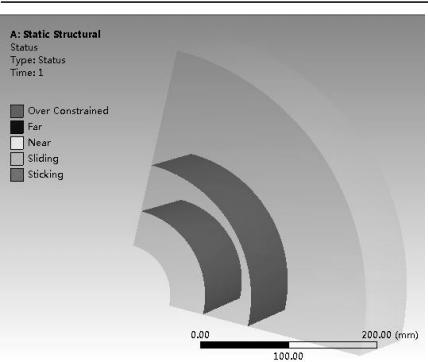

a

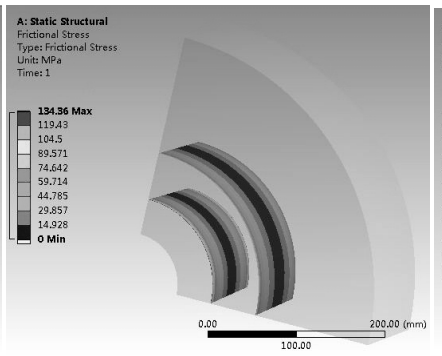

$\mathrm{b}$

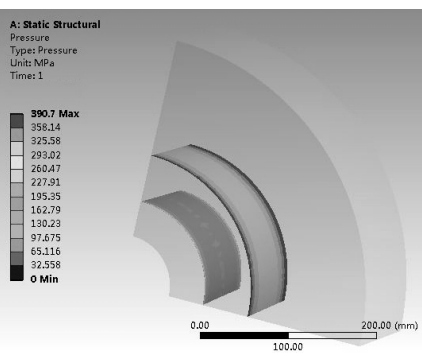

$\mathrm{c}$

Fig. 3. Interference fit surface contact state with no-load. Here and Fig. 4: (a) contact with the physical state; (b) contact friction state; (c) contact normal stress state.

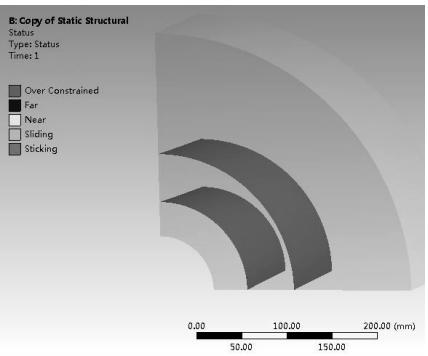

a

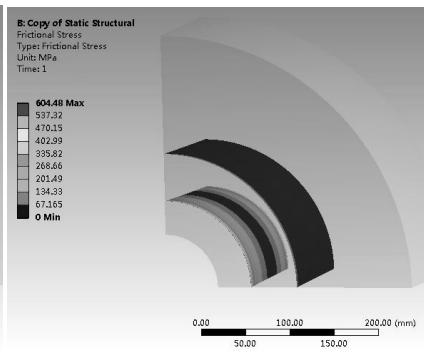

$\mathrm{b}$

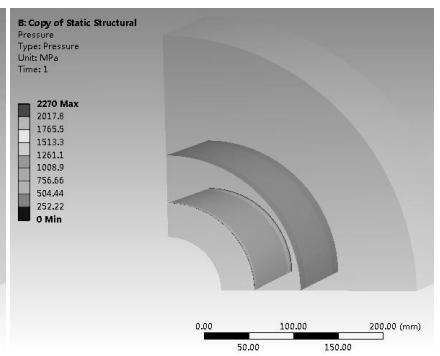

$\mathrm{c}$

Fig. 4. Interference fit surface contact state with maximum load ( $\left.p_{r}=2312 \mathrm{MPa}\right)$.

Fig. 4b, at the middle and outer mating surfaces, the critical state of contact friction force is zero, but this point corresponds to the normal stress of 500-800 MPa in Fig. 4c. The first priority is to ensure that the concave die is a reliable match capable of stable operation.

1.2.2. Tangential Stress State Analysis. According to the fourth strength theory, the maximum principal stress of the concave die is its circumferential stress (tangential stress). This is also the decisive factor of whether the die will have a tangential cracking tendency. Figure 5 shows the maximum principal stress distribution in two cases.

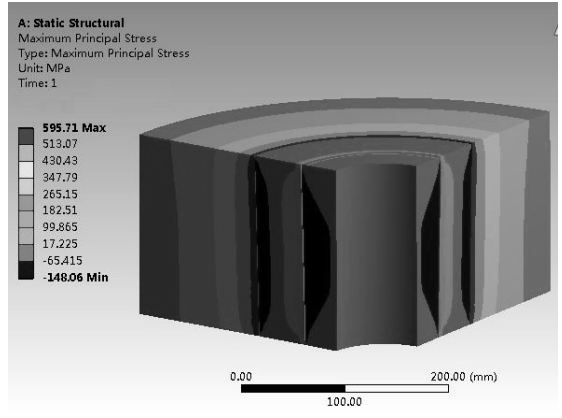

a

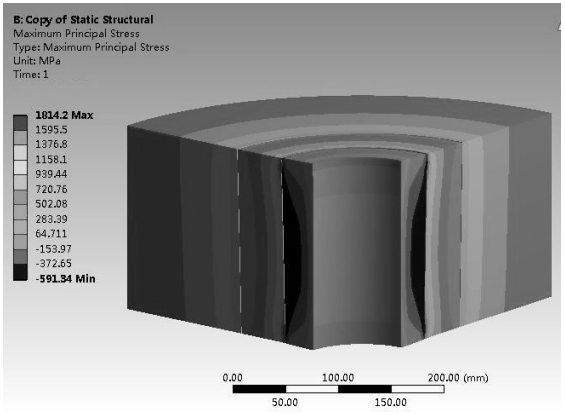

$\mathrm{b}$

Fig. 5. The maximum main stress of sectional female die. Here and Fig. 6: (a) no-load state; (b) loaded state $\left(p_{r}=2312 \mathrm{MPa}\right)$.

As the figure shows, the inner layer and the middle layer bear compressive stress at no load status. The maximum value is $148.06 \mathrm{MPa}$, resulting in a two-layer mating surface; the 
outer layer bears tensile stress, and the maximum is $595.71 \mathrm{MPa}$, resulting in the mating surface with the middle layer. In the loaded state, the inner layer is subjected to compressive stress, while the maximum compressive stress $591.34 \mathrm{MPa}$ appears at the interference fit with the middle layer. The latter has a tensile state under the combined action of tension and compression, and the maximum value is 1814.2 MPa. The simulations of the two states are realistic, and the maximum values are less than the yield limit of the corresponding materials, indicating that the die design is safe.

1.2.3. Radial Stress State Analysis. The radial stress is the intermediate principal stress; in actuality, that is the se-cond principal stress. The ANSYS numerical simulation results are shown in Fig. 6. At no load status, the inner layer and the middle layer bear compressive stress, and the maximum value is $148.13 \mathrm{MPa}$, resulting in the two-layer mating surface; the outer layer bear tensile stress and the maximum is $473.61 \mathrm{MPa}$, resulting in the two-layer mating surface. In the loaded state, the inner layer is subjected to compressive stress, and the maximum compressive stress $77.65 \mathrm{MPa}$ appears at the interference fit with the middle layer. The inner side of the middle layer experiences the combined effects of the inner layer and outer layer, resulting in the tensile stress (up to 1154.2 MPa). The lateral of the middle layer also bears the compressive stress, and its value is about 150 350 MPa; while the entire outer layer bears tensile stresses.

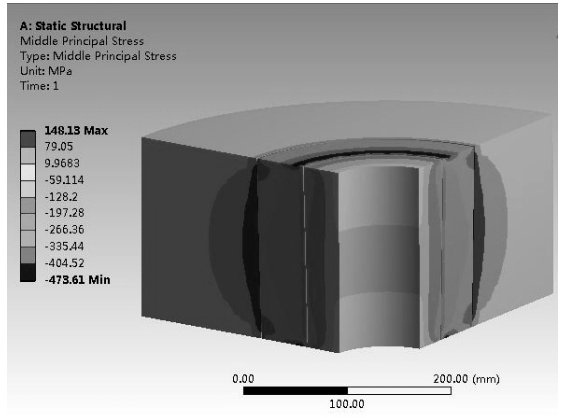

a

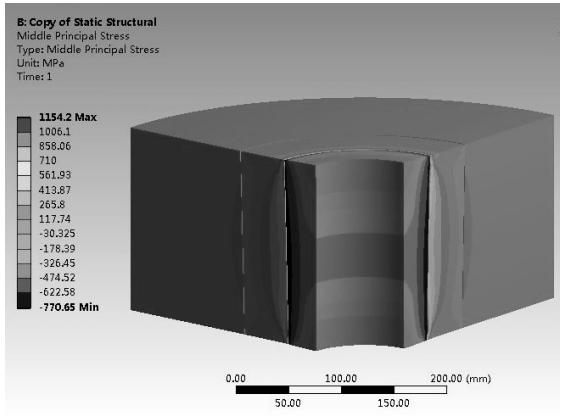

b

Fig. 6. The second principal stress of sectional female die $\left(p_{r}=2312 \mathrm{MPa}\right)$.

Overall, tungsten high speed steel $\mathrm{W} 18 \mathrm{Cr} 4 \mathrm{~V}$ is used for the inner layer, while this material can bear high compressive stress, it cannot bear high tensile stress. The middle and outer layer materials have high toughness and can bear both tensile and compressive stress, conform to the actual working status of the concave die.

\subsection{Die Wear Analysis and Life Prediction.}

1.3.1. Finite Element Numerical Simulation of Die Wear Process. The extrusion process of the piston head causes a strong three-dimensional stress state during which the high-temperature blanks in the combination concave die cavity undergo drastic plastic deformation. The flow of the material transfers with the temperature rise, dislocation slip, hardening, deformation texture and other phenomena. There is strong friction in the mold cavity, especially in continuous mass production; the wear of the concave die is more significant than that of the male die. Therefore, the actual die life refers to the concave die life.

DEFORM software was used for numerical simulation of mold wear as shown in Fig. 7. The most cavity wear is in the abrupt change of the structure size, the side of the die core and the starting position of the draft angle. The radial size of the die is reduced in these positions, the billets are correspondingly reduced in diameter, and the degree of deformation is relatively large, resulting in more serious friction. Because the dimensions either remain unchanged or change slowly, the deformation of the material flow transfer is relatively 


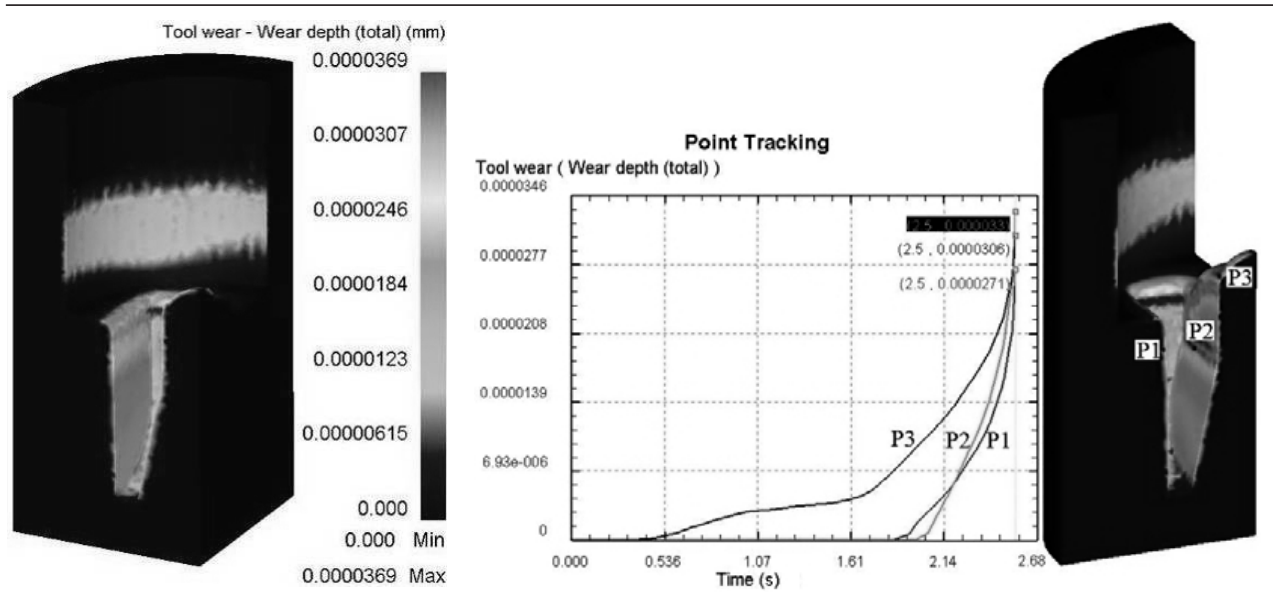

Fig. 7. The distribution of die wear.

stable and has less friction at the upper and lower parts of the die. The outermost corner is the extrusion dead-zone position. The friction is relatively minor, but because of poor fluidity and strong three-way stress, is likely to cause the local stress concentration.

At the upper and lower die, because the dimensions remain unchanged or change slowly, deformation of the material flow transfer is relatively stable, with less friction. The outermost corner is the extrusion dead-zone position, with material flow difficulties. There the friction is relatively minor, but because of poor fluidity and strong three-way stress, is likely to cause local stress concentration [11].

In the more serious wear and tear area take points $P_{1}, P_{2}$, and $P_{3}$, it is seen from Fig. 7 that the maximal wear occurs in the core position $P_{3}$ and its value grows very fast from the beginning of the forming process.

1.3.2. Univariate Linear Regression Equation Analysis. Using the same forming parameters, a number of successive numerical simulations of the piston head forming were carried out, and the maximum wear amount of the die was recorded in each forming simulation, as shown in Table 1. Based on the ten-fold wear of the forming simulation, the die life was derived via the univariate linear regression equation $[6,12]$.

T a b 1 e 1

Die Use Times and Wear Depth Data Sheet

\begin{tabular}{|c|c|c|c|c|c|c|c|c|c|c||}
\hline Use times $m$ & 1 & 2 & 3 & 4 & 5 & 6 & 7 & 8 & 9 & 10 \\
\hline $\begin{array}{c}\text { Wear depth } W \\
\left(\times 10^{-5} \mathrm{~mm}\right)\end{array}$ & 3.69 & 3.58 & 3.51 & 3.43 & 3.36 & 3.31 & 3.25 & 3.21 & 3.18 & 3.16 \\
\hline
\end{tabular}

The data points in Table 1 were plotted in a planar Cartesian coordinate system, and exhibit an inversely proportional relationship between wear depth $W$ and forming number $m$. Thus, the function is expressed by the following equation:

$$
n=x m+\varphi \text {. }
$$

The estimated values $\hat{x}$ and $\hat{\varphi}$ of the coefficients $x$ and $\varphi$ are solved by using the least squares method, define the relevant calculation parameters $n=1 / W, m^{2}, n^{2}=1 / W^{2}$, and $m n$. The results are shown in Table 2. 
L. Q. Yang, Q. Q. Lv, H. M. Zhang, et al.

$\mathrm{T}$ a $\mathrm{b} 1$ e 2

The Least Squares Solutions

\begin{tabular}{||c|c|c|c|c|c||}
\hline$m$ & $W$ & $n=1 / W$ & $m^{2}$ & $n^{2}=1 / W^{2}$ & $m n$ \\
\hline 1 & 0.0000369 & 27100.27 & 1 & 734424688.4 & 27100.271 \\
\hline 2 & 0.0000358 & 27932.96 & 4 & 780250304.3 & 55865.92179 \\
\hline 3 & 0.0000351 & 28490.03 & 9 & 811681723.4 & 85470.08547 \\
\hline 4 & 0.0000343 & 29154.52 & 16 & 849985975.2 & 116618.0758 \\
\hline 5 & 0.0000336 & 29761.9 & 25 & 885770975.1 & 148809.5238 \\
\hline 6 & 0.0000331 & 30211.48 & 36 & 912733545.7 & 181268.8822 \\
\hline 7 & 0.0000325 & 30769.23 & 49 & 946745562.1 & 215384.6154 \\
\hline 8 & 0.0000321 & 31152.65 & 64 & 970487475.9 & 249221.1838 \\
\hline 9 & 0.0000318 & 31446.54 & 81 & 988884933.3 & 283018.8679 \\
\hline 10 & 0.0000316 & 31645.57 & 100 & 1001442077 & 316455.6962 \\
\hline$\sum m=55$ & $\sum W=$ & $\sum n=297665.2$ & $\sum m^{2}=385$ & $\sum n^{2}=$ & $\sum m n=$ \\
& $=0.0003368$ & & & $=88604543731$ & $=1679213.123$ \\
\hline
\end{tabular}

According to the calculation results, order

$$
\left\{\begin{array}{l}
L_{m, m}=\sum_{i=1}^{j}\left(m_{i}-\bar{m}\right)^{2}=\sum_{i=1}^{j} m_{i}^{2}-\frac{1}{j}\left(\sum_{i=1}^{j} m_{i}\right)^{2}, \\
L_{m, n}=\sum_{i=1}^{j}\left(m_{i}-\bar{m}\right)\left(n_{i}-\bar{n}\right)=\sum_{i=1}^{j} m_{i} n_{i}-\frac{1}{j}\left(\sum_{i=1}^{j} m_{i}\right)\left(\sum_{i=1}^{j} n_{i}\right), \\
L_{n, n}=\sum_{i=1}^{j}\left(n_{i}-\bar{n}\right)^{2}=\sum_{i=1}^{j} n_{i}^{2}-\frac{1}{j}\left(\sum_{i=1}^{j} n_{i}\right)^{2} \quad(i, j=1,2, \ldots, 9,10) .
\end{array}\right.
$$

The estimated values $\hat{x}$ and $\hat{\varphi}$ of the coefficients $x$ and $\varphi$ are

$$
\left\{\begin{array}{l}
\hat{x}=\frac{L_{m, n}}{L_{m, m}}=727.9336, \\
\hat{\varphi}=n-\bar{m} \hat{x}=\frac{1}{j} \sum_{i=1}^{j} n_{i}-\left(\frac{1}{j} \sum_{i=1}^{j} m_{i}\right) \hat{x}=25762.8852 .
\end{array}\right.
$$

Thereby, the univariate linear regression equation is

$$
n=x m+\varphi=727.9336 m+25762.8852 \text {. }
$$

The equation fitting curve is shown in Fig. 8, the constant coefficient $R^{2}=0.9633$, the fitting degree is higher. 
1.3.3. Regression Curve Validation. In order to verify the accuracy of the regression curve, a comparison is made between the regression curve values and the software simulation values for the first 20 wear values. $W_{c}$ represents the regression curve values and $W_{s}$ represents the software simulation values. The results are shown in Table 3.

$\mathrm{T}$ a

\section{Regression Curve Accuracy Verification Data Table}

\begin{tabular}{|c|c|c|c|c|c|c|c|c|c|c|}
\hline Working times $m$ & 1 & 2 & 3 & 4 & 5 & 6 & 7 & 8 & 9 & 10 \\
\hline $\begin{array}{l}\text { Simulation values } \\
W_{s}\left(\times 10^{-5} \mathrm{~mm}\right)\end{array}$ & 3.69 & 3.58 & 3.51 & 3.43 & 3.36 & 3.31 & 3.25 & 3.21 & 3.18 & 3.16 \\
\hline $\begin{array}{c}\text { Regression curve } \\
\text { values } W_{c} \\
\left(\times 10^{-5} \mathrm{~mm}\right)\end{array}$ & 3.77 & 3.67 & 3.57 & 3.49 & 3.40 & 3.32 & 3.24 & 3.17 & 3.09 & 3.03 \\
\hline Working times $m$ & 11 & 12 & 13 & 14 & 15 & 16 & 17 & 18 & 19 & 20 \\
\hline $\begin{array}{l}\text { Simulation values } \\
W_{s}\left(\times 10^{-5} \mathrm{~mm}\right)\end{array}$ & 3.11 & 2.93 & 2.87 & 2.78 & 2.73 & 2.66 & 2.61 & 2.56 & 2.52 & 2.46 \\
\hline $\begin{array}{c}\text { Regression curve } \\
\text { values } W_{c} \\
\left(\times 10^{-5} \mathrm{~mm}\right)\end{array}$ & 2.96 & 2.90 & 2.84 & 2.78 & 2.73 & 2.67 & 2.62 & 2.57 & 2.53 & 2.48 \\
\hline
\end{tabular}

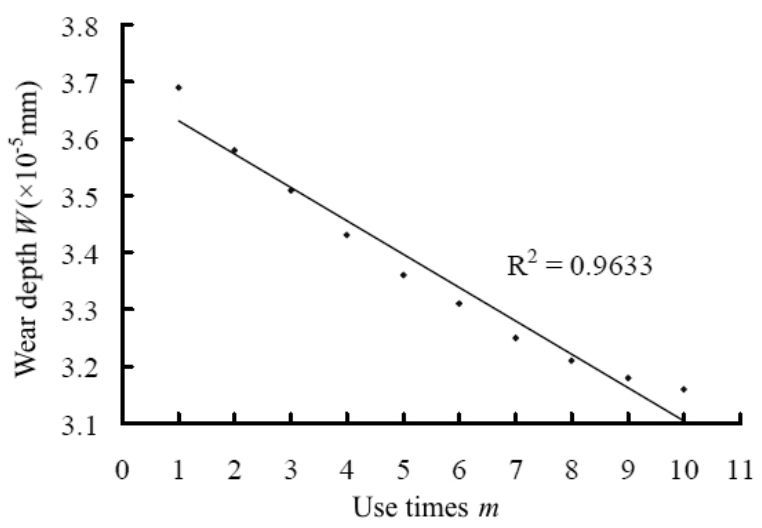

Fig. 8. The univariate linear regression fitting curve.

These 20 discrete points are compared with the regression curve once more. Figure 9 gives the results of this verification. The constant coefficient $R^{2}=0.9936$, which can also be used to predict die life.

1.3.4. Die Life Prediction Calculation. When the mold is operated normally $k$ times, and the cumulative wear depth is $W_{1-k}$, the application limit principle:

$$
W_{1-k}=\sum_{i=1}^{k} \frac{1}{727.9336 m_{i}+25762.8852} \leq \frac{k}{727.9336+25762.8852}=\frac{k}{26490.8788} .
$$

The mold cavity surface is treated with nitriding [13]. The thickness of the nitrided layer is $0.24 \mathrm{~mm}$, and the wear of the nitrided layer was taken as the standard for the die life [8], so order: 


$$
W_{1-k} \leq \frac{k}{26490.8788}=0.24
$$

It was determined that $k=6357.8$. That is, the piston head can manufacture 6357 pieces by the die.

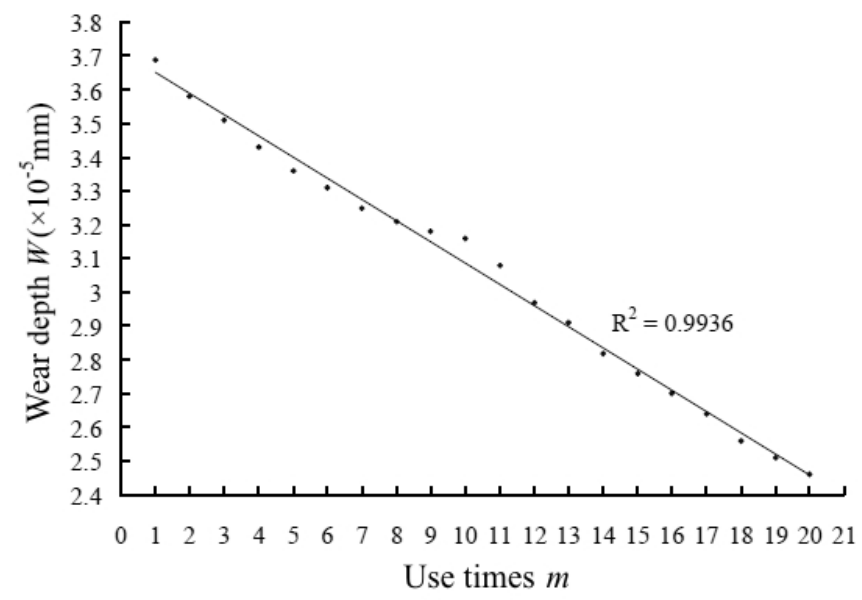

Fig. 9. Curve value and software value verification.

\section{Results and Discussion.}

2.1. Research results. Based on the study of the warm extrusion process as applied to the engine piston head of the corn combine harvester, a three-layer pre-stressed combination concave die was designed. The contact state and structural strength of the reliability for this combination concave die has been verified by ANSYS software. Based on DEFORM software, the Archard wear theory model was adopted. The maximum wear quantity of the die for multiple service was reported, the least square method was used to estimate these discrete points, and the linear regression equation of these discrete points was successfully obtained. The wear quantity service times of the mold were was obtained, and the fitting curve is validated and analyzed. It was determined that the linear regression equation was reliable. Finally, it was found that the design life of the die is about 6357 pieces.

2.2. Limitation Analysis of Die Life Prediction. Die failure contains many uncertain factors, including high temperature and high pressure, friction, alternating heat and cold stress, stress concentration, and additional loading in the extrusion forming process. Therefore, the prediction calculation of the mold life is very complex, and it is difficult to express all of these factors with a simple theoretical model. Thus far, there has been no effective means to accurately predict the mold life. The current finite element analysis is also based on the main impact factors to make it more accurate to the true state of the forecast [14].

\section{Conclusions}

1. The theoretical calculation values of the unilateral interference of the three-layer prestressed combination concave die are 0.9858 and $0.6953 \mathrm{~mm}$, respectively. ANSYS finite element analysis showed that the combination die showed a good contact state in both no-load and full load conditions. The inner die was subjected to compressive stress regardless of load in order to ensure the reliability of the match.

2. The middle and outer layers of the die are subjected to alternating stress along the radial displacement during both no-load and load working cycles, which may cause fatigue 
during long-term use. Tangential stress always dominates between the middle and the outer layers of the combination die, which is the root cause of tangential cracking of the die. Therefore, the die life can be effectively extended if the tangential stress is reduced.

3. In the extrusion process of thermomechanical coupling and three-dimensional stress, the core wear of the composite die is the largest, and it should be adopted as the failure criterion. Based on the Archard wear theory model and the least square method, the linear regression equation was established and the reliability of the equation was validated. Finally, the design life of the die was estimated to be 6357 pieces.

1. P. Miu, Combine Harvesters: Theory, Modeling, and Design, CRC Press of Taylor \& Francis Group, Boca Raton (2016).

2. M. R. M. Aliha, A. Bahmani, and S. Akhondi, "Fracture and fatigue analysis for a cracked carabiner using 3D finite element simulations," Strength Mater., 47, No. 6, 890-902 (2015).

3. C. J. Chen, Q. D. Wang, D. D. Yin, and W. J. Dong, "Research process in piston materials of combustion engine," Mater. Rev., 23, No. 8, 62-65 (2009).

4. R. Matsumoto, Y. Osumi, and H. Utsunomiya, "Reduction of friction of steel covered with oxide scale in hot forging," J. Mater. Process. Tech., 214, No. 3, 651-659 (2014).

5. Q. Q. Lv, Q. M. Guan, L. Q. Yang, and X. K. Wang, "The optimization design study of warm extrusion forming technology for piston head of semi-processed," $A d v$. Mater. Res., 803, 375-378 (2013).

6. L. Q. Yang, Key Technology Research of Warm Extrusion Forming for Engine Piston Head [in Chinese], Guizhou University, Guiyang (2013).

7. S. Z. Zhang, Extrusion Technology and Mold Design [in Chinese], Chemical Industry Press, Beijing (2009).

8. G. Y. Lin, D. Feng, X. Y. Zheng, et al., "Analysis of influence of extrusion times on total die wear based on Archard theory," J. Centr. South Univ. (Sci. and Tech.), 40, No. 5, 1245-251 (2009).

9. D. Landgrebe, A. Sterzing, N. Schubert, and M. Bergmann, "Influence of die geometry on performance in gradation extrusion using numerical simulation and analytical calculation," CIRP Annals, 65, No. 1, 269-272 (2016).

10. X. Bai, X. T. Wang, L. P. Sun, et al., "Edge effect analysis for sphere-cylinder combined shell of mono-shell submarine," J. Harbin Eng. Univ., 34, No. 4, 409-414 (2013).

11. L. Zou, J. C. Xia, X. Y. Wang, and G. Hu, "Optimization of die profile for improving die life in the hot extrusion process," J. Mater. Process. Tech., 142, No. 3, 659-664 (2003).

12. Z. M. Sun, Research on Warm Extrusion of Gear Based on FEM [in Chinese], Hefei University of Technology, Hefei (2006).

13. Y. Birol and B. Yuksel, "Performance of gas nitrided and AlTiN coated AISI H13 hot work tool steel in aluminium extrusion," Surf. Coat. Tech., 207, 461-466 (2012).

14. D. H. Kim, H. C. Lee, B. M. Kim, and K. H. Kim, "Estimation of die service life against plastic deformation and wear during hot forging processes," J. Mater. Process. Tech., 166, 372-380 (2005). 